\title{
The Insulin Response to Glucose Infusion in Normal Human Pregnancy
}

\author{
P. M. Fisher ${ }^{1}$, H. W. Sutherland ${ }^{1}$, and P. D. Bewsher ${ }^{2}$ \\ Departments of ${ }^{1}$ Obstetrics and Gynaecology and ${ }^{2}$ Therapeutics and Clinical Pharmacology, University of Aberdeen, Aberdeen, Scotland
}

Summary. To study insulin response and insulin sensitivity a glucose infusion test was devised. Twenty normal non-pregnant and twenty normal pregnant women had an intravenous glucose tolerance test followed by a glucose infusion test. In a normal pregnant group at $38-40$ weeks gestation $(n=20)$ the plasma insulin response was found to be 3.7 times greater than that observed in a normal non-pregnant group $(\mathrm{n}=20)$, while in the normal pregnant group the insulin sensitivity index was only 18 per cent of that observed in the non-pregnant group. Intravenous glucose tolerance in the non-pregnant women was observed to correlate with the insulin sensitivity index $(\mathrm{r}=0.61, \mathrm{p}<0.05)$ but in the pregnant women it correlated with the insulin response $(\mathrm{r}=0.66, \mathrm{p}<0.01)$. These findings support the hypothesis that in the non-pregnant state intravenous glucose tolerance may be primarily related to insulin sensitivity while during pregnancy it may be related to the degree of compensatory hyperinsulinism.

Key words: Human pregnancy, glucose infusion test, insulin response, insulin sensitivity, intravenous glucose tolerance test, human placental lactogen, progesterone, oestradiol $17-\beta$.

The physiological aspects of maternal energy metabolism in human pregnancy are not clearly understood, but it is believed that metabolic realignments occur in order to provide the fetus with an advantageous nutritional environment for growth and development. Maternal hyperinsulinism is thought to be a secondary compensatory mechanism related to the maintenance of maternal glucose homeostasis [1]. Peripheral insulin responses have been studied in pregnancy using $25 \mathrm{~g}$ single or double dose glucose injection techniques [2, 3, 4]. Since these methods do not relate the glucose dose to the distribution compartment the insulinogenic stimulus may not be constant between subjects. Comparative analysis of such individual insulin responses is thereby limited.

Using a high dose glucose infusion method Cerasi and Luft have shown that a meaningful index for comparison may be obtained by relating the insulin response to the glycaemic stimulus. Their extensive studies $[5,6]$ demonstrate clearly that the glucose infusion test (GIT) can provide an assessment of pancreatic beta cell function which may reveal degrees of metabolic abnormality beyond the limits of the standard glucose tolerance tests.

The present study was undertaken to define more clearly the physiological insulinogenic adaptation of human pregnancy in relation to glucose homeostasis. A glucose infusion test and an intravenous glucose tolerance test (IVGTT) were used.

\section{Materials and Methods}

\section{Patient Selection}

Twenty normal non-pregnant nulliparae, and twenty normal pregnant women ( 15 primigravidae and 5 multiparae) at 38 to 40 weeks gestation, were selected for study. None had a history of abnormal glucose tolerance or any features of potential diabetes [7]. None had any other diseases or were taking any drugs. None of the non-pregnant nulliparae had ever taken the contraceptive pill. All the pregnant women were sure of the date of their last menstruation, and had normal pregnancies before and after the tests. The mean ages of the non-pregnant women and the pregnant women were $22.9 \pm 1.6$ years and $24.5 \pm 4.2$ years respectively. All subjects were below the 85th centile standard of body weight [8]. In the pregnant group this was estimated from the calculated 
pre-pregnant weight [9]. The percentages of ideal body weight for the non-pregnant group and the pregnant group were $101 \pm 6$ and $98 \pm 6$ respectively. The infant birth weights in the pregnant group were all below the 95 th centile [10].

The study was approved by the Hospital Ethical Committee, and each patient gave her informed consent.

\section{Procedures}

Intravenous Glucose Tolerance Test. After an overnight fast from 2200 hours, and a 30 -minute rest, each woman had a 25 g IVGTT at 1000 hours. The fasting venous samples were withdrawn at $5 \mathrm{~min}$ intervals from an antecubital vein. Twenty-five $\mathrm{g}$ glucose $(50 \mathrm{~g} / 100 \mathrm{ml})$ was injected into the opposite antecubital vein over $3 \mathrm{~min}$. Thereafter venous samples were taken at $4,10,20,25,30$, $35,40,45,50$ and $60 \mathrm{~min}$ from completion of the injection. All samples were centrifuged immediately and plasma glucose was estimated by a glucose oxidase method in a Beckman glucose analyser. The test result was expressed as the Increment Index which is calculated using the formula $\frac{69.3}{t_{1 / 2}}[11] . t_{y_{2}}$ is derived using the incremental plasma glucose decay curve, that is, using the fasting plasma glucose level as the base-line.

Glucose Infusion Test. Two to seven days later each woman had a GIT after an overnight fast from $2200 \mathrm{~h}$. Prior to the test the bladder was emptied. The right and left antecubital veins were cannulated and the subject placed in a recumbent position with at least $45^{\circ}$ left lateral tilt to the pelvis after a 30 min rest. A loading dose of $400 \mathrm{mg}$ of glucose $/ \mathrm{kg}$ body weight was injected as a $50 \mathrm{~g} /$ $100 \mathrm{ml}$ solution over $3 \mathrm{~min}$, and an adjustable infusion of $20 \mathrm{~g} /$ $100 \mathrm{ml}$ glucose was started in the same arm.

Two $\times 1.5 \mathrm{ml}$ fasting venous samples were withdrawn from the opposite arm at $5 \mathrm{~min}$ intervals. On completion of the loading dose similar samples were withdrawn at $0,1,2,3,4,5,7$, and $10 \mathrm{~min}$, and every $5 \mathrm{~min}$ thereafter until $90 \mathrm{~min}$. All samples were decanted into heparinised containers. Plasma glucose was estimated within $2 \mathrm{~min}$ of withdrawal in the fasting, 4 and $10 \mathrm{~min}$ samples and in every sample thereafter until $90 \mathrm{~min}$ by the glucose oxidase method in a Beckman Glucose Analyser. This provided the means of maintaining the plasma glucose level at around 260 to $270 \mathrm{mg} /$ $100 \mathrm{ml}$ over the $90 \mathrm{~min}$ test period by adjusting the glucose infusion.

On completion of the test the bladder was emptied, the urine volume measured, and urinary glucose estimated by the glucose oxidase method. The volume of infused glucose was recorded. The plasma was separated from all samples and stored at $-18^{\circ} \mathrm{C}$ for plasma insulin analysis [12].

In the pregnant group a $5 \mathrm{ml}$ fasting venous sample was also withdrawn, the plasma separated and stored at $-18^{\circ} \mathrm{C}$ for later estimation of plasma progesterone, human placental lactogen, and oestradiol $17-\beta$.

\section{Analysis of Results}

\section{Summated Insulin Response}

Having observed the plasma insulin response over $90 \mathrm{~min}$ and by applying circulating insulin half-life values, the summated amount of insulin delivered to the circulation at any point up to 90 min may be estimated. The non-pregnancy and pregnancy circulating insulin half-life values reported by Burt and David- son [13] were used for this calculation, i. e. for up to $20 \mathrm{~min}$ half-life values of $4.0 \mathrm{~min}$ and $4.3 \mathrm{~min}$ and for $20 \mathrm{~min}$ and over of 8.5 and $8.7 \mathrm{~min}$ for the non-pregnant and pregnant women respectively.

The calculation of the summated insulin response was based on the following formula of Thorell and co-workers [14].

Formula 1: Summated Insulin Response ${ }_{t}=I_{t}+k$. Area $_{\mathrm{t}}$

Formula 2: $\mathrm{k}=\frac{\log 2}{\mathrm{t}_{1 / 2}}$

where $\mathrm{I}=$ Insulin concentration $(\mu \mathrm{U} / \mathrm{ml}), \mathrm{t}=$ time $(\mathrm{min}), \mathrm{k}=$ elimination rate constant (fraction of plasma pool $/ \mathrm{min}$ ), and $t_{1 / 2}=$ circulating insulin halflife $(\mathrm{min})$.

The summated insulin response at $t$ was dependent on the summated area at $t$ and the constant $k$ which changed at $20 \mathrm{~min}$. The following insulin response correction factor was added to values calculated from $20 \mathrm{~min}$ when the longer circulating insulin half-life values were applied to the early insulin response phase up to $10 \mathrm{~min}$.

Insulin Response Correction Factor $=\mathrm{I}_{10}+\mathrm{k}$.

Area 10.

\section{Insulin Delivery Rate}

The rate of insulin delivery to the circulation is based on the formula:

$\mathrm{f}=\mathrm{kI}+\frac{\mathrm{dI}}{\mathrm{dt}}$

where $\mathrm{f}=$ Insulin Delivery Rate $(\mu \mathrm{U} / \mathrm{ml} / \mathrm{min})$.

\section{Insulin Sensitivity Index}

The concept is based on the principle that an assessment of the biological sensitivity to endogenous insulin may be provided by relating the amount of glucose infused to maintain the plasma glucose level constant to the summated plasma insulin response over the same period. The following formula was applied:

ISI $=\frac{\text { Total glucose infused }(\mathrm{mg})-\text { urinary glucose }(\mathrm{mg}) / \mathrm{kg} \text { body weight }}{\text { Summated } 90 \text {-min plasma insulin response }(\mu \mathrm{U} / \mathrm{ml})}$

The ISI was estimated for each individual.

Results are presented as mean \pm SD values. Student's $t$ test of significance was applied throughout. For lognormal distributions this test was applied using the logarithms of the values. 

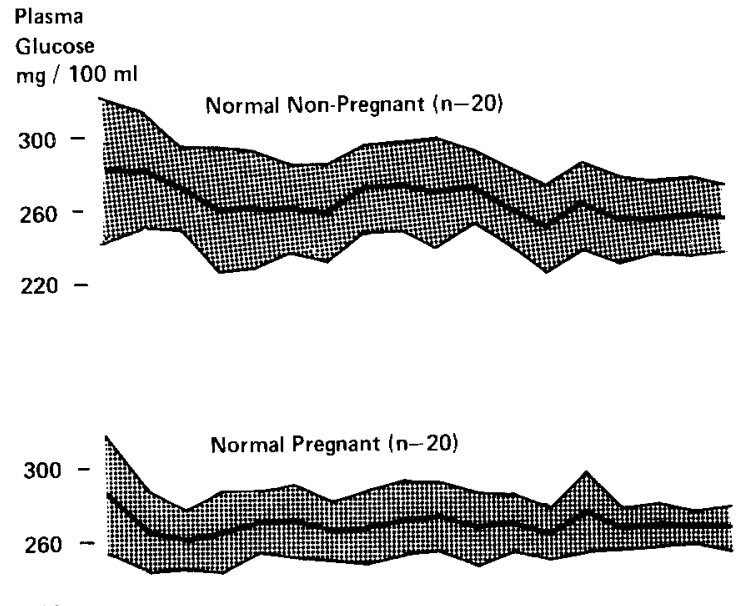

$220-$

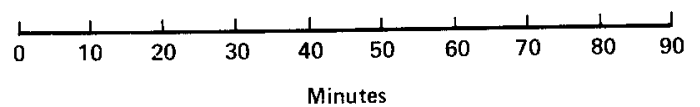

Fig. 1. Plasma glucose levels maintained at infusion in normal nonpregnant and normal pregnant women. Mean (solid line) \pm SD (shaded area). The plasma glucose was elevated by an IV loading dose of $400 \mathrm{mg}$ glucose $/ \mathrm{kg}$ body weight over $3 \mathrm{~min}$ and maintained by a variable infusion of $20 \mathrm{~g} / 100 \mathrm{ml}$ glucose

\section{Results}

\section{Fasting Plasma Glucose and Insulin}

The mean fasting plasma glucose was significantly lower in the pregnant women at $74 \pm 5 \mathrm{mg} / 100 \mathrm{ml}$ compared with $83 \pm 8 \mathrm{mg} / 100 \mathrm{ml}$ for the non-pregnant women $(p<0.01)$. The mean fasting plasma insulin was significantly higher in the pregnant group at $14 \pm 5 \mu \mathrm{U} / \mathrm{ml}$ compared with $9 \pm 4 \mu \mathrm{U} / \mathrm{ml}$ for the non-pregnant group $(\mathrm{p}<0.01)$.

\section{Intravenous Glucose Tolerance}

In all subjects the increment index of the IVGTT was normal, i.e. above 2.97 . The normal nulliparous group had a mean increment index of $5.57 \pm 1.82$ compared with the lower mean of $4.40 \pm 1.51$ for the normal pregnant group. The difference was significant $(\mathrm{p}<0.05)$.

\section{Glucose Infusion Test}

The mean plasma glucose levels maintained at infusion are shown in Figure 1. This confirms that the levels in each group were maintained at around

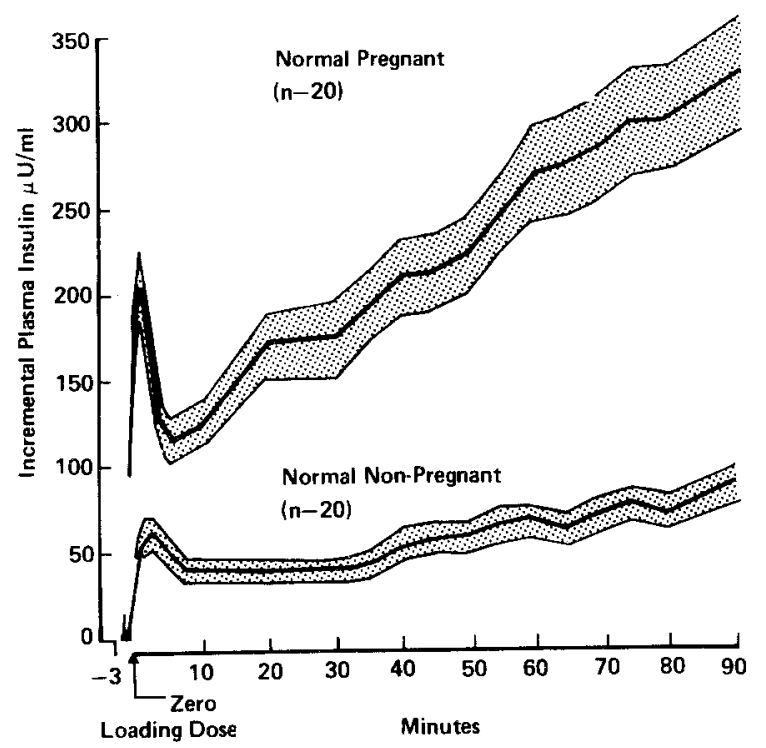

Fig. 2. Biphasic plasma insulin responses in normal non-pregnant and normal pregnant women. Mean (solid line) \pm SEM (shaded area). In each group the plasma glucose was constant at around $260-270 \mathrm{mg} / 100 \mathrm{ml}$ over $90 \mathrm{~min}$. The immediate first phase responses are followed by the later second phase response

$260-270 \mathrm{mg} / 100 \mathrm{ml}$. The overall mean of the individual mean plasma glucose levels was $264 \pm 15 \mathrm{mg} /$ $100 \mathrm{ml}$ for the non-pregnant group and $268 \pm 8 \mathrm{mg} /$ $100 \mathrm{ml}$ for the pregnant group.

\section{Plasma Insulin Response}

When the incremental plasma insulin values were plotted against time, biphasic plasma insulin response patterns were observed in all subjects. Figure 2 represents the mean incremental plasma insulin response over $90 \mathrm{~min}$ in each group. The mean first and second phase insulin responses were greater in the pregnant group.

From these mean incremental insulin responses the mean summated 90 -min insulin responses were calculated for each group. In the pregnant group $2041 \mu \mathrm{U}$ insulin/ml plasma had been delivered compared with $554 \mu \mathrm{U}$ insulin/ml plasma for the nonpregnant group. This indicated an insulin response 3.7 times greater in the pregnant group.

\section{Plasma Insulin Delivery Rate}

The peripheral plasma insulin delivery rates were calculated for each group. In the pregnant group there 
Table 1. First and second phase plasma insulin responses and summated 90 minute plasma insulin responses in normal non-pregnant and normal pregnant women. The first phase response was calculated to 4 and $3 \mathrm{~min}$ for the non-pregnant and pregnant women respectively. Thereafter the second phase response continued to $90 \mathrm{~min}$. The summated $90 \mathrm{~min}$ insulin response included the first and second phases

\begin{tabular}{|c|c|c|c|c|c|c|}
\hline \multirow[t]{2}{*}{ Group } & \multicolumn{2}{|c|}{$\begin{array}{l}\text { First phase insulin } \\
\text { response }(\mu \mathrm{U} / \mathrm{ml})\end{array}$} & \multicolumn{2}{|c|}{$\begin{array}{l}\text { Second phase insulin } \\
\text { response }(\mu \mathrm{U} / \mathrm{ml})\end{array}$} & \multicolumn{2}{|c|}{$\begin{array}{l}\text { Summated } 90 \text { minute } \\
\text { insulin response }(\mu \mathrm{U} / \mathrm{ml})\end{array}$} \\
\hline & Mean & Range & Mean & Range & Mean & Range \\
\hline Normal non-pregnant $(\mathrm{n}=20)$ & 105 & $25-289$ & 449 & $89-1017$ & 554 & $114-1244$ \\
\hline Normal pregnant $(\mathrm{n}=20)$ & $280^{\mathrm{a}}$ & $130-640$ & $1760^{\mathrm{a}}$ & $635-3090$ & $2041^{\mathrm{a}}$ & $765-3667$ \\
\hline
\end{tabular}

${ }^{\mathrm{a}} \mathrm{p}<0.001$ compared with normal non-pregnant values

was an initial very rapid rate of insulin delivery which rose to a peak of $63 \mu \mathrm{U} / \mathrm{ml} / \mathrm{min}$. This was followed by a latent phase of $2 \mathrm{~min}$. The onset of the second phase commenced at $3 \mathrm{~min}$ and from $5 \mathrm{~min}$ the rate tended to be constant over the 90 min with a mean delivery rate of $23 \mu \mathrm{U} / \mathrm{ml} / \mathrm{min}$.

In the non-pregnant group the first phase delivery rate rose rapidly to a peak of $21 \mu \mathrm{U} / \mathrm{ml} 7 \mathrm{~min}$. There was no latent period before the second phase became evident at $4 \mathrm{~min}$. Throughout the second phase delivery rate tended to be constant with a mean of $6 \mu \mathrm{U} /$ $\mathrm{ml} / \mathrm{min}$.

\section{Individual Summated Plasma Insulin Responses}

Using the second phase onset times indicated by the insulin delivery rate data the summated first phase and summated second phase insulin responses were calculated for each group. The means and ranges are shown in Table 1 along with the summated $90 \mathrm{~min}$ insulin response data. Compared with the non-pregnant group the means in each case were significantly greater in the pregnant group.

\section{Insulin Sensitivity Index}

The mean insulin sensitivity index in the pregnant group was $0.53 \pm 0.21$. The mean insulin sensitivity index in the non-pregnant group was $3.10 \pm 1.67$. The difference was highly significant $(\mathrm{p}<0.001)$. The low value in pregnancy of $18 \%$ of the non-pregnant value indicates a reduction in biological sensitivity to endogenous insulin in late normal pregnancy.

\section{Correlation Data Analysis}

Significant positive correlations were found between the first and second insulin response phases for both the normal non-pregnant group $(\mathrm{r}=0.82 \mathrm{p}<0.01$ ) and for the normal pregnant group $(\mathrm{r}=0.53$ $\mathrm{p}<0.05)$.

In the non-pregnant group when three "low" insulin responders [5] were excluded a significant positive correlation was observed between insulin sensitivity index and increment index $(\mathrm{r}=0.61$ $\mathrm{p}<0.05$ ). There was no significant correlation between insulin response and increment index.

In the pregnant group there was a significant positive correlation between the summated first phase insulin response and increment index $(\mathrm{r}=0.65$ $\mathrm{p}<0.01$ ). No other insulin response or insulin sensitivity correlations with increment index were significant.

In the normal pregnant group the mean fasting plasma progesterone was $446 \pm 159 \mathrm{nmol} / \mathrm{l}$, the mean fasting plasma human placental lactogen was $77 \pm 24 \mu \mathrm{g} / \mathrm{l}$, and the mean fasting plasma oestradiol $17-\beta$ was $29.4 \pm 6.3 \mu \mathrm{g} / \mathrm{l}$. A significant positive correlation was observed between fasting plasma progesterone and increment index of the IVGTT $(\mathrm{r}=0.63 \mathrm{p}<0.05)$. No other correlations were significant.

\section{Discussion}

This study confirms previous observations of diminished intravenous glucose tolerance in late pregnancy $[7,15,16]$. The corresponding decrease in fasting plasma glucose and elevation in fasting plasma insulin levels are also well known $[2,3,16]$.

In all subjects the insulin response to the loading dose followed by a maintenance infusion was clearly biphasic. In a glucose dose response study Cerasi and co-workers [17] found sigmoidally distributed dose response relationships similar for the early and late insulin response phases and suggested that basically the same mechanism controls each phase. The observed correlation between first and second phase insulin responses supports their conclusions.

Insulin half-life is not significantly affected by pregnancy [18]. The values adopted for this study [13] are not only similar for the non-pregnant and pregnant states but are also close to others which have been independently assessed for the early phase $[19,20]$ and for the later phase [21] of the insulin 
decay curve. Furthermore these values were relevant for this study since they had been similarly derived in non-pregnant and pregnant women over prolonged study periods $(60 \mathrm{~min})$.

The mean insulin response in late pregnancy was 3.7 times greater than that observed in non-pregnant women. Since the GIT is essentially a stress test of $\beta$ cell function this increase may not quantitatively relate exactly to the physiological state and may represent the degree of enhanced $\beta$-cell reactivity to glycaemic stimulation only. This increase is similar to the estimates of Spellacy and co-workers [22] and Burt and co-workers [4], but the mechanism is not clear. The specific gestational insulinogenic factors are unlikely to have a direct $\beta$-cell effect since the fasting plasma insulin level in the pregnant group was only $50 \%$ greater than the mean in the non-pregnant group. The mode of action of these factors may therefore be related to the potentiation of the glucose induced insulin response as suggested by Cerasi and Luft [23] as a mechanism for other insulinogenic agents.

Theoretically the insulin sensitivity index provides an index of biological sensitivity to endogenous insulin. As insulin passes into the systemic circulation it is partially metabolised by the liver, but the relative activity in terms of glucose disposal in the non-pregnant and pregnant states is not known $[24,25]$. Unaccountable hepatic metabolic activity may therefore be a source of error inherent in the insulin sensitivity index. In the pregnant women no account could be taken of the infused glucose transfer to the fetal compartment. Since this error would tend to raise the insulin sensitivity index the values obtained may tend to underestimate the degree of insulin resistance in late pregnancy.

The results in this study are consistent with the hypothesis that the raised insulin response during pregnancy may be a compensatory mechanism related to primary gestational insulin resistance. Glucose tolerance in the "fed" state is thereby maintained. In this study the insulin sensitivity index in the normal pregnant group was only $18 \%$ of that in the normal nulliparous group while the pregnancy hyperinsulinism factor of $370 \%$ mathematically fails to compensate adequately. This observed deficit in insulinogenic compensation may account for the diminished IV glucose tolerance of late pregnancy.

Correlation analysis of the data suggests that in the non-pregnant state insulin sensitivity may be the primary factor influencing glucose tolerance while during pregnancy the insulin response to the injected glucose may be the dominant influence. For the purposes of these analyses it was reasonable to exclude from the data the "low" insulin responders since the low insulin response may be an indicator of potential pathology [5] and may be associated with a compensatory increase in hepatic insulin sensitivity [26]. These results support the conclusions of Reaven and Olefsky [27] who found only a "modest correlation" between insulin response and $\mathrm{K}$ value of the IVGTT in non-pregnant subjects, and on reviewing other work $[28,29,30,31,32]$ they concluded that there was "no unique high degree of correlation" between the insulin response and glucose tolerance. The present study is consistent with the hypothesis that during pregnancy when diminished biological sensitivity to endogenous insulin would tend to depress maternal glucose homeostasis the degree of glucose tolerance which is maintained is dependent on the efficiency of the compensatory insulinogenic mechanism.

In an attempt to assess the role of the placental hormones as mediators of the pregnancy metabolic realignments, correlation was sought between fasting plasma progesterone, human placental lactogen and oestradiol 17- $\beta$ and increment index, the insulin response and insulin sensitivity index data. The significant positive correlation observed between fasting plasma progesterone and increment index suggests that this hormone may have a role. However, this conclusion is limited by the failure to observe an associated correlation with insulin response. The failure to observe any other associations is not at variance with the belief that each of these hormones may influence pregnancy glucose homeostasis $[33,34,35$, $36,37]$, but this failure does suggest that the gestational realignments are subject to multifactorial regulation.

Acknowledgements. This study was carried out during the tenure of a British Diabetic Association Research Fellowship by P. M. F. We are grateful to Professor A. I. Klopper, Department of Obstetrics and Gynaecology, University of Aberdeen, for plasma oestradiol $17-\beta$, progesterone, and human placental lactogen estimations. We gratefully acknowledge the technical assistance of Miss Fiona MacGregor and the secretarial assistance of Miss Mary Grassick.

\section{References}

1. Freinkel N, Herrera E, Knopp RH, Ruder HJ (1970) Metabolic realignment in late pregnancy. A clue to diabetogenesis. In: Camerini-Dávalos R, Cole HS (eds) Early diabetes. Supplement I to Advances in metabolic disorders. Academic Press, New York, p 205-215

2. Spellacy WN, Goetz FC, Greenberg BZ, Ells J (1963) Plasma insulin in normal late pregnancy. N Engl J Med 268: 988-991

3. Bleischer SJ, O'Sullivan JB, Freinkel NB (1964) Carbohydrate metabolism in pregnancy. V. The inter-relationships of glucose insulin and free fatty acids in late pregnancy and postpartum. N Engl J Med 271: 866-872 
4. Burt RL, Leake NH, Rhyne AL (1969) Glucose tolerance during pregnancy and the puerperium. A modification with observations on serum immunoreactive insulin. Obstet Gynecol 33: 634-641

5. Cerasi E, Luft R (1967) The plasma insulin response to glucose infusion in healthy subjects and in diabetes mellitus. Acta Endocrinol (Kbh) 55: 278-304

6. Cerasi E (1974) Metabolic consequences of low insulin response in non-diabetic subjects. In: Malaisse WJ, Pirart J (eds) Diabetes. Proceedings of the Eighth Congress of the International Diabetes Federation, Brussels. Excerpta Medica Foundation, Amsterdam, p 341-345

7. Fisher, PM, Hamilton PM, Sutherland HW, Stowers JM (1974) The effect of pregnancy on intravenous glucose tolerance. Br J Obstet Gynaecol 81: 285-290

8. Kemsley, WFF (1951) Body weight at different ages and heights. Ann Eugenics 16: 316-334

9. Hytten FE, Leitch I (1971) The physiology of human pregnancy, 2nd ed. Blackwell, Oxford, p 279

10. Thomson AM, Billewicz WZ, Hytten FE (1968) The assessment of fetal growth. Br J Obstet Gynaecol 75: 903-916

11. Duncan LJP (1956) Intravenous glucose tolerance test. Q J Exp Physiol 41: 85-96

12. Hales CN, Randle PJ (1963) Immunoassay of insulin with insulin-antibody precipitate. Biochem J 88: 137-146

13. Burt RL, Davidson IWF (1974) Insulin half-life and utilisation in normal pregnancy. Obstet Gynecol 43: 161-170

15. Thorell JI, Nosslin B, Sterky G (1973) Estimation of the early insulin response to intravenous glucose injection. $\mathrm{J} \mathrm{Lab}$ Clin Med 82: 101-110

15. O'Sullivan JB (1970) Gestational diabetes and its significance. In: Camerini-Dávalos RA, Cole HS (eds) Early diabetes. Supplement I to Advances in metabolic disorders. Academic Press, New York, p 339-346

16. Edstrom K, Cerasi E, Luft R (1974) Insulin response to glucose infusion during pregnancy. A prospective study of high and low insulin responders with normal carbohydrate tolerance. Acta Endocrinol (Kbh) 75: 87-104

17. Cerasi E, Fick G, Rudemo M (1974) A mathematical model for the glucose induced insulin release in man. Eur $\mathbf{J}$ Clin Invest 4: 267-278

18. Bellmann O, Hartmann $E$ (1975) Influence of pregnancy on the kinetics of insulin. Am J Obstet Gynecol 122: 829-833

19. Lind T, Bell S, Gilmore E, Huisges HJ, Schally AV (1977) Insulin disappearance rate in pregnant and non-pregnant women, and in non-pregnant women given G.H.R.I.H. Eur J Clin Invest 7: 47-51

20. Stimmler L (1966) Disappearance rate of insulin. Lancet II: 1078

21. Ørskov H, Christensen NJ (1969) Disappearance rate of injected human insulin in juvenile diabetic, maturity onset diabetic, and non-diabetic subjects. Diabetes 18: 653-659

22. Spellacy WN, Goetz FC, Greenberg BZ, Ells J (1965) Plasma insulin in normal early pregnancy. Obstet Gynecol 25: $862-865$

23. Cerasi E, Luft R (1973) Pathogenesis of genetic diabetes mellitus. Further development of a hypothesis. Mt Sinai J Med NY 40: $334-349$
24. Cerasi E, Hallberg D, Luft R (1970) Simultaneous determination of insulin in brachial and portal veins during glucose infusion in normal and pre-diabetic subjects. Horm Metab Res 2: 303-304

25. Blackard WG, Nelson NC (1971) Portal and peripheral vein immunoreactive insulin concentration following tolbutamide administration. Diabetes 20: 168-170

26. Cerasi E, Wahren J, Luft R, Felig P, Hendler R (1973) The regulation of splanchnic glucose production in subjects with low insulin response - a compensatory mechanism in prediabetics? Eur J Clin Invest 3: 193-200

27. Reaven GM, Olefsky JM (1974) Relationship between insulin response during the intravenous glucose tolerance test, rate of fractional glucose removal and the degree of insulin resistance in normal adults. J Clin Endocrinol Metab 38: 151-154

28. Samols E, Marks V (1965) Interpretation of the intravenous glucose test. Lancet I: $462-463$

29. Buchanan KD, McKiddie MT (1967) The normal insulin response to glucose. The relationship between blood sugar and plasma insulin. Diabetologia 3: 460-464

30. Lawrie EG, Soeldner JS, Hampers CL (1970) Glucose metabolism and insulin secretion in uraemic, pre-diabetic and normal subjects. J Lab Clin Med 76: 603-615

31. Lerner RL, Porte D (1971) Relationship between intravenous glucose loads, insulin responses and glucose disappearance rate. J Clin Endocrinol Metab 33: 409-417

32. Sterky G, Thorell JI (1973) Early insulin response to glucose stimulation in siblings of juvenile diabetics. Acta Endocrinol (Kbh) 73: 721-730

33. Yen SSC (1973) Endocrine regulation of metabolic homeostasis during pregnancy. Clin Obstet Gynecol 16:130-147

34. Grumbach MM, Kaplan SL, Sciarra JJ, Burr IM (1968) Chorionic growth-hormone-prolactin (CGP): Secretion, disposition, biological activity in man; postulated function as "growth hormone" of second half of pregnancy. Ann NY Acad Sci 148: 501-531

35. Beck P, Doughaday WH (1967) Human placental lactogen Studies of its acute metabolic effect and disposition in normal man. J Clin Invest 46: 103-110

36. Costrini NV, Kalkhoff RK (1971) Relative effects of pregnancy. Estradiol and progesterone on plasma insulin and pancreatic islet insulin secretion. J Clin Invest 50: 992-999

37. Oakley NW, Monier D, Wynn V (1973) Diurnal variation in oral glucose tolerance; Insulin and growth hormone changes with special reference to women taking oral contraceptives. Diabetologia 9: 235-238

Received: February 19, 1979, and in revised form: February 1, 1980

Peter M. Fisher, M. D., M. R. C. O. G.

Department of Obstetrics and Gynaecology

University of Aberdeen

Foresterhill

Aberdeen, Scotland 